\title{
PRESCHOOLERS' WORD LEARNING AND STORY COMPREHENSION DURING SHARED BOOK READING
}

By

\author{
SOFIA R. JIMENEZ
}

\author{
Thesis \\ Submitted to the Faculty of the \\ Graduate School of Vanderbilt University \\ in partial fulfillment of the requirements \\ for the degree of \\ MASTER OF SCIENCE
}

in

Psychology

August, 2015

Nashville, Tennessee

Approved:

Professor Megan Saylor

Professor Daniel Levin 


\section{ACKNOWLEDGEMENTS}

This research was supported by the Psychology and Human Development departmental funds. I would like to sincerely thank the members of the Language Development Lab for their help with recruitment, data input and organization, and the parents who generously brought their children in to participate in this study. Thank you as well to the preschool teachers and directors that were accommodating in welcoming us into their schools allowing us conduct research. The members of our weekly graduate student meetings: Daniel Levin, Lewis Baker, Maria Osina and Claire Weaver, have provided insight on study design and data interpretation. And finally a huge thank you to my advisor and mentor, Dr. Megan Saylor, for her enthusiasm and invaluable guidance for this project from the little details to the big ideas. 


\section{TABLE OF CONTENTS}

Page

ACKNOWLEDGEMENTS ............................................................................ ii

\section{Chapter}

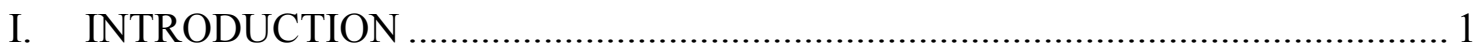

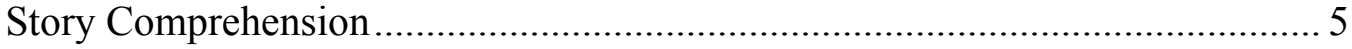

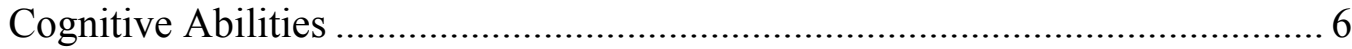

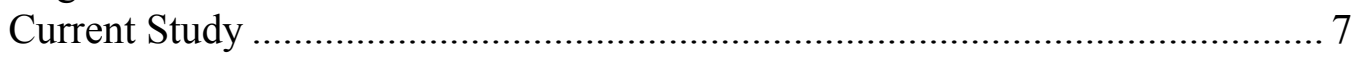

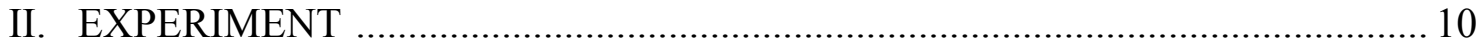

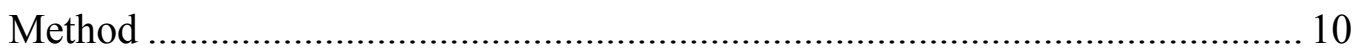

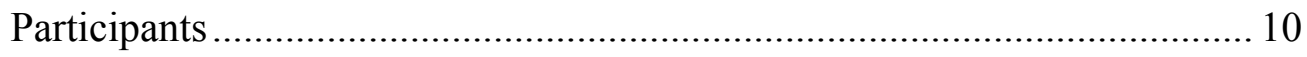

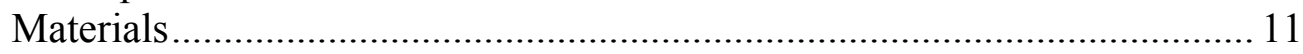

Procedure and Design ................................................................. 12

Individual Differences Measures ......................................................... 15

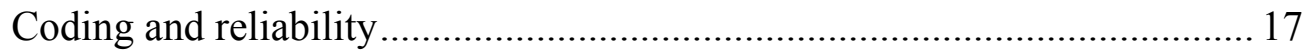

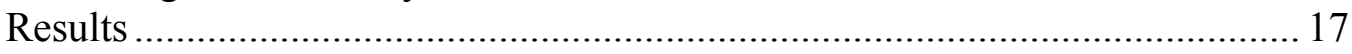

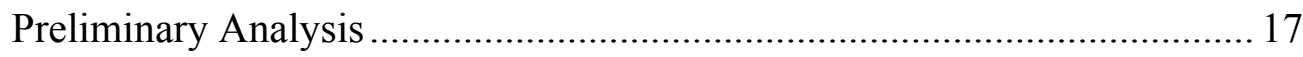

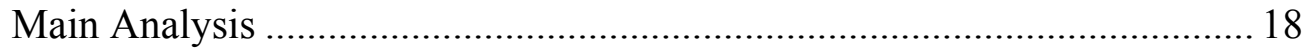

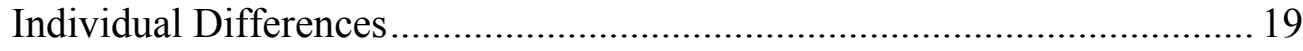

III. DISCUSSION .................................................................................... 22

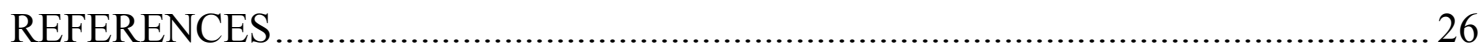




\section{CHAPTER I}

\section{INTRODUCTION}

Before children can read on their own, joint book reading can facilitate the development of language and later reading skills (Biemiller, 2003; Bus, Van IJzendoorn \& Pellegrini, 1995). The effects of joint reading on children's emerging literacy behaviors are long-lasting and in some circumstances, may offset negative effects of low socio-economic status (Bus, Van IJzendoorn \& Pellegrini, 1995; Scarborough \& Dobrich, 1994; Scarborough, Dobrich, \& Hager, 1991). As a result, many studies have investigated reading techniques that best support vocabulary acquisition in the context of joint reading episodes. One popular technique is dialogic reading, which encourages adults to ask open-ended questions and elicit a dialogue while reading a book to a child (Mol, Bus, de Jong \& Smeets, 2008; Whitehurst et al., 1988; Whitehurst, et al., 1994). Although typical dialogic reading techniques involve interrupting the story to provide instruction, it is not clear whether such interruption is necessary for vocabulary learning and if interruptions might also be ineffective for children with less robust ancillary cognitive skills. In what follows, we investigate whether the placement of instruction affects acquisition of new vocabulary and understanding of the storyline. In addition, we ask whether children's non-linguistic cognitive skills, such as memory, interact with the placement of instruction.

Dialogic reading was initially developed to help children be participatory during joint-reading sessions by encouraging extra-textual talk (Whitehurst et al, 1988). One 
aspect of dialogic reading is asking children "wh-" questions such as "what do you think will happen" or, "where is she?" to elicit extended dialogue and encourage productive language during a story reading episode. Adults respond to children's utterances and scaffold questions to the child's abilities and familiarity with the particular book. Since its development, researchers have explored different aspects of dialogic reading, including level of interactivity (Justice, 2002; Walsh \& Blewitt, 2006), and question types (Strasser, Larrain \& Lissi, 2013; Zucker, Justice, Piasta \& Kaderavek, 2010), and their role in encouraging children's vocabulary growth.

Researchers interested in the effects of dialogic instruction on word learning have investigated gains in vocabulary size and acquisition of specific words that are included in the story. Several intervention studies have revealed that that regularly engaging in dialogic reading leads to gains in children's expressive vocabulary as measured by the Expressive One Word Picture Vocabulary Test (Hargrave \& Sénéchal, 2000; Mol, Bus, de Jong \& Smeets, 2008; Whitehurst et al, 1988). Other work has borrowed elements of the dialogic technique to ask whether children can learn specific vocabulary items that are included in the story (Ewers \& Brownson, 1999; Sénéchal \& Cornell, 1993; Walsh \& Blewitt, 2006). Children in these studies are asked questions during storybook reading that are specific to novel vocabulary and not always open-ended and thus represent a deviation from the Whitehurst's (1988) initial formulation of the dialogic technique.

Adaptations of dialogic reading include questions that are specific to vocabulary items in the story interrupt the reading midstream (Blewitt, Rump, Shealy, \& Cook, 2009; Justice, 2002; Sénéchal \& Cornell, 1993; Sénéchal, 1997; Walsh \& Blewitt, 2006). This is because the dialogic questioning and instruction occurs when the vocabulary item 
appears in the text. During dialogic reading, children are encouraged to be participatory, which means they have to manage many tasks at once; 1) following the narrative presented in the story, 2) contributing to mini-conversations as the story is stopped and probes are introduced and 3) learning the new words presented in the story. On one hand, presenting the instruction in the context of the story may increase children's attention to vocabulary items and associated narrative content. On the other hand, dialogic reading may present difficulties for some children who find the interruptions disruptive and the information offered in difficult to encode.

Previous work provides an incomplete picture of the effects of story interruption on vocabulary acquisition. In one study, Blewitt, et al. (2009) manipulated both the difficulty of questions (e.g. low demand: "How many wheels does the pram have?" and high demand: "Do you think the ticket man lives in the pagoda? Why (or why not)?") and their placement (i.e., either interrupting the story or after the story). They compared these styles of presentation to a condition in which there were no vocabulary-relevant questions or comments made. They found no effect of either questions placement or level of cognitive difficulty on 3-year-olds' receptive or expressive word acquisition on trained items - that is, children learned words equally well regardless of placement or difficulty. However, children in this study were read the stories containing the novel words repeatedly over a period of six weeks. Familiarity with the storyline may have offset difficulties associated with interruptions. Additionally, story comprehension was not tested in this study, so although children performed equally well on vocabulary measures, we do not know if they were tracking the storyline effectively when the reading was interrupted. Finally, equal performance across conditions in and of itself, does not 
provide information about the abilities that supported children's success. It is possible that children achieved equivalent performance across the two conditions, but relied on different cognitive or linguistic strengths to do so.

Consistent with this possibility, in another study, Reese \& Cox (1999) compared three semi-naturalistic reading styles: two required active participation during the story: a describer style, which included questions about story events and a comprehender style, which included questions about meaning. In a third reading style, a performance-oriented style, questions were asked before and after the story and the story itself was read straight through with no questions. They found that children's vocabulary size at pretest predicted which reading style would be most effective for them: children who had larger initial vocabularies gained more words when the story was read without interruption, and discussion happened before or after the story. Children with lower vocabulary skills learned more words with the "describer" style. However, because the presentation styles varied on four dimensions (question type, amount, difficulty and placement), it is difficult to determine why language skills predicted which reading style worked best. One possibility is that other abilities that tend to be correlated with vocabulary size might have contributed. For instance, children with larger vocabularies tend to exhibit more developed memory abilities (Gathercole, Willis, Emslie \& Baddeley, 1992). Even still, this study suggests that instructional styles interact with children's prior abilities.

Taken together, these studies raise questions about the role of instructional placement on vocabulary acquisition. For one, it is unclear if there will be differences in word learning between interrupting instruction and non-interrupting instruction if stories and instruction are presented a single time. It may be that repeated presentation of a story 
may reduce sensitivity to differences in children's word learning performance. Previous studies vary the number of times a story is read and vocabulary instruction is given. The amount of effort necessary to teach children words is sometimes massive: participants were exposed to the novel word four to twelve times before learning it, even with rich, dialogic supports (Walsh \& Blewitt, 2006; Blewitt, et al., 2009). Children's gains in vocabulary during dialogic reading also tend to be modest. For example, in one study they learned on average 1.35 of 10 words that are presented to them (e.g., Sénéchal \& Cornell, 1993), in another they recognized 3.33 of 10 (Justice, 2002) and in another they learned 4.5 out of 10 (Sénéchal, 1997). These findings point to possible limitations with the dialogic approach - it may be labor intensive with modest gains in vocabulary learning. Determining whether a single presentation of the story and instruction will influence word learning and may lead to more efficiency in instruction.

It is also unclear from these previous studies if instructional placement affects story comprehension. Participant's story comprehension has often not been measured in dialogic reading studies despite being an important factor in joint book reading that may be related to how well children learn words. Finally, the role of ancillary cognitive skills in regard to instructional placement has not been addressed. For example, it is unclear if children are using memory skills to a greater extent when instruction is interrupting the storyline than when instruction takes place separately from the story reading.

\section{Story Comprehension}

Reading to children is an opportunity to encourage story comprehension skills and other oral language skills (Isbell, Sobol, Lindauer \& Lowrance, 2004). According to the 
National Early Literacy Panel (NELP), more complex oral language skills, like listening comprehension and grammar might me more predictive of later reading comprehension outcomes than expressive or receptive vocabulary (NELP 2008, Dickinson, Golinkof \& Hirsh-Pasek, 2010). However, many studies that have investigated dialogic reading have focused exclusively on vocabulary learning (Blewitt et al., 2009; Ewers \& Brownson, 1999; Hargrave \& Sénéchal, 2000; Justice, 2002; Sénéchal \& Cornell, 1993; Sénéchal, 1997; Strasser, Larrain \& Lissi, 2013; Walsh \& Blewitt, 2006; Wilkinson \& HoustonPrice, 2012; Zucker, et al., 2010) and in studies that have measured story comprehension vocabulary acquisition was not tested (Isbell et al., 2004; Morrow, 1984). In addition, the rare studies that have tested both vocabulary and story comprehension typically are those that use storybook videos, and both story comprehension and vocabulary acquisition improved through dialogic questioning (Spencer, Goldstein, Sherman et al., 2012; Strouse, O’Doherty, \& Troseth, 2013).

An unexplored possibility is that children may be favoring either vocabulary or the storyline, so even though there are positive changes to both, individually participants are only improving on one or the other. Alternatively, vocabulary and story comprehension could be positively correlated. Support for this comes from Strasser, Larrain \& Lissi (2013), who found that elaborating vocabulary words was correlated with better story comprehension.

\section{Cognitive Abilities}

Variability in preschoolers' ability to learn words and information from picture books has been explained, in part, by their receptive vocabulary (Sénéchal, Thomas \& 
Monker, 1995; Reese \& Cox, 1999). Variations in prior vocabulary knowledge have been shown to affect how children learn from interactive book reading; unsurprisingly, children who start out with a larger vocabulary size, learn more words (Blewitt, et al., 2009; Ewers \& Brownson, 1999; Hindman, Connor, Jewkes \& Morrison, 2008; Sénéchal, et al., 1995).

However, non-linguistic cognitive abilities, like memory and executive function may also contribute to children's vocabulary learning during dialogic reading. Previous research from non-dialogic reading studies suggests that both memory and executive function may support learning when reading stories in school age children. For example, in 8-11 year old children working memory has been shown to be an independent predictor of reading comprehension when verbal ability and word reading was controlled for (Cain, Bryant \& Oakhill, 2004). Other executive function tasks have also been shown to contribute to reading comprehension in older children, ages 9-15 (Sesma, Mahone, Levine, Eason, \& Cutting, 2009). On the other hand, phonological working memory measured by a non-word repetition task was not shown to impact word learning in kindergarten (6-year-old) children in an active-participation word-learning task (Ewers \& Brownson, 1999). These studies still do not elucidate the role of working memory and executive function for 3-5 year-old, pre-literate children in word learning or story comprehension. In the current study, we aim to explain how these factors interact.

\section{Current Study}

We manipulate the placement of vocabulary instruction, while controlling for quality of instruction and exposure to the storybook containing the vocabulary. In one 
condition, interactive vocabulary instruction is placed within the story (the inside condition) and in the other condition; instruction is placed either before or after the story (the outside condition). There are three possible outcomes. The first is that proximate context is important for learning words, so children will learn more words in the inside condition. Participants' may glean more information about an unknown word directly from the story line, thus it would be beneficial to elaborate on an unknown word when it comes up in the story. This hypothesis aligns with research showing the virtues of dialogic reading (Mol, et al. 2008; Sénéchal \& Cornell, 1993; Whitehurst et al., 1988). An alternative hypothesis is that the inside condition strains a preschooler's cognitive load, so children will learn better in the outside condition. Additionally performance could be the same in both conditions, which would be consistent with findings from Blewitt et al. (2009). Learning is measured both by vocabulary acquisition and story comprehension. Vocabulary learning will be measured by the selection of target's picture, generalization of the target words and elicited production, while story comprehension will be measured with questions about story events.

Another goal of the study is to determine which cognitive abilities relate to word learning and story comprehension. In the current study, we will not only be testing receptive vocabulary (through the PPVT-IV), but we will also test cognitive abilities that may influence word learning and story comprehension. Verbal short-term memory will be tested using the forward digit span, which is seen as a developmentally appropriate pure working memory task (Carlson, 2005). Another measure of working memory will be provided by the self-ordered pointing task modeled after one used by Craig \& Nation (2007). The day/night task describes participants' inhibitory ability and also their ability 
to self-monitor, since they have to keep the rule in mind and realize when they have switched back to their prepotent response (Montgomery \& Koeltzow, 2010; Simpson \& Riggs, 2005). We expect that the inside condition will require more cognitive resources because it requires more task switching. 


\section{CHAPTER II}

\section{EXPERIMENT}

\section{Method}

\section{Participants}

Eighty-three preschool children (range 36-72 months, $M=54$ months, 38 Females, 45 Males) were recruited from childcare centers and state birth records in the southeastern United States. Six additional children were recruited and not included in the analysis for non-compliance $(\mathrm{n}=1)$, biased responding $(\mathrm{n}=4)$ and non-proficiency in English $(n=1)$. Participants were typically developing, had intact hearing, and heard English in their household $70 \%$ of the time or more.

Demographic surveys revealed that $48 \%$ of mothers had a post graduate degree or some graduate school, $45 \%$ had a college degree or some college, and $2 \%$ had a technical/AA degree. Four mothers did not respond to this question. $45 \%$ of participants' families reported an income of $\$ 150,000$ or more per year, $17 \%$ reported an income between $\$ 100,000$ to $\$ 150,000$ per year, $13 \%$ reported an income between $\$ 100,000$ and $\$ 50,000$ per year, and $14 \%$ of families reported an income of less than $\$ 50,000$ per year. Ten participants' parents did not respond. 


\section{Materials}

Participants were read an illustrated storybook created for the purposes of this experiment. It contained six low-frequency target words (i.e. rebar, gingham, Nicaragua, rickshaw, ocarina and pitaya) that were not easily nameable using a higher-frequency synonym. The words were chosen to avoid the mutual exclusivity bias (Merriman \& Bowman, 1989). The story was about a brother and sister who traveled to Nicaragua with their mom, but became separated from her and are reunited at the end. The story was written to maintain preschoolers' interest and create an ecologically valid shared reading situation.

For a vocabulary pretest, posttest and generalization test, picture cards were created illustrating objects found in the storybook, some of which were target words. See Figure 1 for an example illustration. In the pre/post-test and an elicited production test the illustrations were taken from the storybook. The generalization test included cards of the same objects as the pre/post-test, but they were photographs of the items instead of drawings.

Twenty day/night cards were created for a day-night stroop task to measure inhibition. The day card depicted a yellow sun with a white background while the night card had a white crescent moon with a black background.

Materials were created for a self-ordered pointing task that measured visual working memory. The task was divided into three increasingly difficult levels, each with it's own stimuli. The first set had four pages with four items randomly arranged on cardstock paper on each page (i.e., lamp, glasses, hammer and umbrella). For each page of the task, items appeared in different locations, to ensure participants were tracking the 
items and not the locations. The second set consists of eight different fruit on eight pages and the third set consists of ten animals on ten pages. Children were shown one page at a time and asked to point to a new object each time.

Parents were given questionnaires about the home literacy environment of the child, including how many hours per week the child was read to and how many children's books were in the home.

\section{Procedures and Design}

Participants were randomly assigned to one of two between-subjects conditions so that age and gender were matched. In the inside condition $(\mathrm{N}=41, \mathrm{M}$ age $=54.8$ months, range $=36-72$, 19 Females, 22 Males) children were given label training for the target words directly after the sentence with the word read. In the outside condition $(\mathrm{N}=42, \mathrm{M}$ age $=54$ months, range $=38-72,19$ Females, 23 Males) they were either given the label training for all the target words before or after the story was read so the story was not interrupted. Since there were no differences in performance if the label training occurred before or after the story (word learning: $\mathrm{t}(40)=.83, \mathrm{p}=41, d=.26$; story comprehension: $\mathrm{t}(40)=-.25, \mathrm{p}=.81, d=.08)$, we analyze data from these two presentation styles together. All participants were shown illustrations of the target words as they appeared in the storybook while the label training was given. Children were also offered the same information about novel vocabulary in each condition.

Participants in both conditions were first pretested on the target vocabulary items, then did label training along with hearing the book, vocabulary post-tests, a story comprehension test and four individual differences measures (i.e., digit-span, self-ordered 
pointing task, day-night stroop and PPVT). Item order for story comprehension and vocabulary questions was counterbalanced across participants. In addition, after the story and vocabulary instruction, half the participants were asked the vocabulary questions first and half were asked the story comprehension questions first.

\section{Pretest}

To ensure the target words were unfamiliar to the participants, they were pretested in a three-option forced-choice task during the pre-test. They were asked to select a card with the picture of the target word among two distractors: a depiction of a different target item and a non-named object that would be illustrated in the storybook. The distractors were designed to be difficult because children could not chose the picture-card based on what they remember learning about, there were always two options that they had learned about.

\section{Label Training}

Participants in the inside condition were then read the storybook. When a target word appeared in the story, the experimenter would define the word. The instructional dialogue was interactive and followed this pattern:

Experimenter: "Do you know what an ocarina is?"

Child responds.

Experimenter: "An ocarina is a musical instrument you can play with your mouth. Do you see that?"

Child responds.

Experimenter: Can you say ocarina?

Child repeats word.

This pattern of dialogue was repeated for each of the target vocabulary items. 


\section{Post-Test}

After the story was read and the vocabulary instruction was completed, participants were re-tested on the target words in a three-item forced choice task similar to the one given at pretest. In the case that children chose more than one word-card, the final item was recorded. Children were tested on all six of the target words. The order of words presented was counterbalanced across participants, as were the locations of the three choices per trial.

\section{Generalization Test}

Next participants were given the generalization test where they choose the target word's referent among photographs that they have never seen before. The items were counterbalanced across participants, as they were in the vocabulary post-test.

\section{Elicited Production}

After the generalization test, participants were asked to name the six items in a production test when presented with illustrations of the target words. Children were told to name the item on the card. If they said they did not know or they took longer than five seconds to answer, the experimenter asked if they wanted a hint. The hint provided would be the first syllable of the target word. If they did not produce the word after the hint and another five seconds the experimenter progressed to the next word. The order that the words were presented was counterbalanced across participants.

\section{Conditions}

The outside condition follows the same general pattern, however the instructional dialogue took place either before or after the story was read. They were taught all six words in the same order as they appeared in the story and presented with the same 
illustration as the children in the inside condition during the instruction. There were no performance differences between the children who received instruction before the story and children who received instruction after the story so they are combined in our analysis.

\section{Story comprehension}

Following the elicited production test, participants in both conditions were asked six questions about the events of the story with three answer choices. These questions ranged from the beginning to the end of the story and did not include any of the target words. For example, a child would be asked, "Who told Ben and Amy that they were going on a trip?" and given the answer choices: their teacher, their mom or their dog. One of the choices was correct, one was a near distractor that included an element of the story and one choice was a far distractor that did not appear in the story.

\section{Individual Differences Measures}

Participants were tested on cognitive and linguistic measures that might influence their performance on the storybook task. Their individual differences were measured either after a five-minute break (in the lab) or during different visit (in the childcare centers). The digit span was administered first, followed by the day/night stroop, then the self-ordered pointing task and finally the PPVT-IV.

\section{Digit span}

To determine short-term memory capacity of each child and measure phonological working memory, we used a forward digit-span test. Children were told they were going to play a game where the experimenter said some numbers and then they 
were asked to say the numbers right after. Participants were given two numbers initially and this was repeated for the first level. Then they were given two trials with three numbers, four numbers, etc. until a child made a mistake on both number sequences in a level. The number of sequences a child correctly repeated was recorded as their score.

\section{Day/Night Stroop task}

In this task children were to say "day" when presented with the night card and “night" when presented with day card (see Materials section for description). Participants practiced the task until they demonstrated understanding of the rules. Participants were given one point for correct responding. Self-corrects were recorded but not included in their final score. There were twenty trials.

\section{Self-ordered pointing task}

This task measured visual working memory and is modeled after a task described by Craig \& Nation (2007). Children are told that they will be seeing pages with things on them and they have to point to a new thing and every time the experimenter flips the page until they have pointed to every item in a set. The first set had four items and was primarily for practice and to insure understanding of the rules. The second set had eight items and the third set had ten items. Participants were given one point for each new item they pointed to. The self-ordered pointing task requires that the participant keep in mind what they have pointed to in the past while pointing to new objects.

\section{Peabody Picture Vocabulary Test}

To determine the participants' receptive vocabulary size the Peabody Picture Vocabulary Test-IV (PPVT-IV) was administered (Dunn \& Dunn, 2007). Children are given a word and have to choose its picture out of a grid of four pictures. 


\section{Coding and Reliability}

Twenty percent of the participants' pre-test, post-test, generalization and story comprehension tasks $(n=16)$ were recoded by a research assistant. There was $97 \%$ agreement between the initial coding and the recoding.

\section{Results}

We investigated whether the benefits of eliciting an instructional dialogue would persist even when the vocabulary was presented outside of the story. If the traditional placement of dialogic instruction is more beneficial for word learning and story comprehension, we would expect to see improved performance for both in the inside condition. However if the inside condition is more demanding on preschoolers' cognitive abilities, then story comprehension and/or word learning would be negatively affected. We also investigate if cognitive abilities interacted with the placement of interactive instruction.

\section{Preliminary Analysis}

Independent sample t-tests determined that the participants in the two conditions (i.e. inside and outside) were matched on age, sex, maternal education and income, number of children's books in the home, number of hours read to per week as well as PPVT-IV, digit span, inhibition, and self-ordered pointing task scores. Refer to table 1 of means and standard deviation for these variables. 


\section{Main Analysis}

To investigate differences in children's vocabulary learning across the two conditions we first conducted a 2 (condition: inside, outside) X 2 (phase: pre-test, posttest) repeated-measures mixed ANOVA. Condition was between participants and phase was within. The analysis revealed a significant difference between the pretest performance and the posttest performance $\left(\mathrm{F}(1,81)=35.85, \mathrm{p}<.001, \eta_{p}{ }^{2}=.31\right)$, but there was no effect of condition, $\mathrm{F}(1,81)=1.08, \mathrm{p}=.30, \eta_{p}{ }^{2}=.01$ and there was no interaction, $\mathrm{F}(1,81)=.74, \mathrm{p}=.39, \eta_{p}{ }^{2}=.01$. The placement of the instructional dialogue did not influence performance: children learned words equally well across the two presentation styles. There were no differences in performance between conditions on pretest $(\mathrm{t}(81)=0.07, \mathrm{p}=0.94, d=.02)$, post-test $(\mathrm{t}(81)=1.18, \mathrm{p}=0.24, d=.26)$, generalization $(\mathrm{t}(81)=0.22, \mathrm{p}=0.83, d=.05)$ or elicited production $(\mathrm{t}(80)=.55, \mathrm{p}=.59$, $d=.12$ ). Table 2 provides the mean target word selection for each group.

Additionally, children selected the target at above chance levels in both the posttest when they picked the novel word from the illustrations they had seen before in the outside $(\mathrm{t}(41)=7.89, \mathrm{p}<.001, d=2.47)$ and inside $(\mathrm{t}(40)=6.53, \mathrm{p}<.001, d=2.06)$ conditions and in the generalization task when they chose the correct picture, even though they had never seen the specific photographs before in the outside $(\mathrm{t}(41)=4.42, \mathrm{p}<.001$, $d=1.32)$ and inside $(\mathrm{t}(40)=4.79, \mathrm{p}<.001, d=1.51)$ conditions. See Figure 2.

For the elicited production task, participants produced an average of 1.13 words in the outside condition and 1.01 words in the inside condition (No difference, $\mathrm{t}(80)=0.54$, $\mathrm{p}=.58, d=.12)$. Since participants did not show high performance on elicited production in either condition, we will not discuss these results further. This performance pattern is 
common in recent studies (Justice, 2002), especially if children are only taught the target words one time (Sénéchal \& Cornell, 1993).

For story comprehension items, children in the outside condition answered an average of 3.45 out of 6 questions correctly while children in the inside condition answered an average of 3.88 correctly. There were no differences between conditions $(\mathrm{t}(81)=-1.60, \mathrm{p}=0.11, d=.36)$ We found that mean story comprehension responding was above chance in both the outside $(\mathrm{t}(41)=8.02, \mathrm{p}<.001, d=2.51)$ and the inside $(\mathrm{t}(40)=9.63, \mathrm{p}<.001, d=3.05)$ conditions. Interrupting the storyline in the inside condition did not significantly lower children's story comprehension scores relative to the outside condition.

Further, we investigated whether there were trade-offs between story comprehension and word learning. We found that there were not. In fact, there was a modest positive correlation between comprehension and vocabulary post-test $(\mathrm{r}(83)=$ $0.28, \mathrm{p}<.05)$ and the generalization measure $(\mathrm{r}(83)=.34, \mathrm{p}<.05)$. Children who learned the words effectively were also understanding and remembering the storyline better.

\section{Individual Differences}

We investigated whether cognitive abilities interact with instructional placement. We predicted that children with more robust memory and inhibition abilities would be better able to handle the demands of inside condition because it required participants to keep more than one thing in mind at a time. To address this hypothesis, we performed linear regression separately on the inside and outside conditions. 
Since previous research has found a correlation between a participants' vocabulary size and their word learning performance, we investigated if this pattern emerged in our data. We found that the standardized scores of the PPVT-IV did not correlate with our pretest scores $(\mathrm{r}(80)=.04, \mathrm{p}=.75)$, posttest scores $(\mathrm{r}(80)=-.07, \mathrm{p}=$ $.53)$, or generalization scores $(\mathrm{r}(80)=.18, \mathrm{p}=.12)$. However, the PPVT-IV was correlated with story comprehension $(\mathrm{r}(80)=.25, \mathrm{p}<.05)$. As a result of these analyses, we include scores on the PPVT-IV as a variable in our analyses of story comprehension, but not in our analyses of word learning.

\section{Predicting Word Learning}

First, we performed regressions to predict a participant's word learning, which was measured using a combined vocabulary post-test and generalization score. This was done with four predictors: age, digit-span, inhibition, SOPT separately by condition. The regression for the outside condition was not significant $(\mathrm{F}(4,36)=0.36, \mathrm{p}=0.84)$ and there were no significant predictors (See table 3 for beta weights). The regression for the inside condition, however, was significant $\left(\mathrm{F}(4,40)=7.80, \mathrm{p}<.001, \mathrm{R}^{2}{ }_{\text {Adjusted }}=0.41\right)$ and the independent significant predictor was digit-span $(\mathrm{t}(36)=3.17, \mathrm{p}<.01$, See Table 4).

\section{Predicting Story Comprehension}

We used the five measures (age, digit-span, inhibition, self-ordered pointing task and the PVVT-IV) to predict story comprehension in both conditions. For the outside condition the model was significant $\left(F(5,36)=3.24 \mathrm{p}<.05, \mathrm{R}^{2}{ }_{\text {ddjusted }}=0.24\right)$, but there was no independent significant predictors, except for the standardized PPVT-IV scores, which marginally predicted story comprehension performance $(\mathrm{t}(36)=1.87, \mathrm{p}=.07$, See Table 5). In the inside condition the model was significant $(\mathrm{F}(5,40)=5.67, \mathrm{p}<.001$, 
$\left.\mathrm{R}_{\text {Adjusted }}^{2}=0.37\right)$ Digit-span was an independent significant predictor $(\mathrm{t}(40)=2.21, \mathrm{p}<$ .05 , see Table 6) as was SOPT $(\mathrm{t}(36)=2.56, \mathrm{p}<.05)$. 


\section{CHAPTER III}

\section{DISCUSSION}

Despite the popular convention of teaching words when they appear in the story during dialogic reading, the effect of instructional placement on word learning and how it interacts with individual cognitive abilities has remained unclear. Here, we found that interactive vocabulary instruction was effective in teaching children new words, but its placement inside the story was not necessary — children learned equally well when instruction occurred before or after the story. Additionally, we found that the comprehension of the storyline was not affected in either condition. Story comprehension was positively correlated with measures of word learning, which indicates that participants who understood and remembered the story events also retained the information about the target words and they may be abilities that support each other.

We found some support for the hypothesis that placement of instruction would be differentially affected by the cognitive abilities of our participants. Digit span significantly predicted word-learning performance in only the inside condition. Memory abilities may play a larger role in vocabulary acquisition when words are taught during the story, than when they are taught before or after the story. These results suggest that the inside condition, or more traditional dialogic instruction, may put a larger demand on preschooler's cognitive load than when the story is told separately from the vocabulary instruction. These memory abilities not only help with word learning and generalization, 
but also with story comprehension. Story comprehension in the inside condition was predicted by both digit span (short-term memory) and SOPT (working memory), while in the outside condition, story comprehension was only marginally predicted by the PPVTIV (vocabulary knowledge). This indicates participants may rely on stronger executive function abilities and flexibly update working memory to retain the story line with many extended interruptions.

We hypothesized that the multitasking nature of dialogic reading would make it difficult for children to learn words and the storyline and therefore predicted that there might be trade-offs between these abilities. Word learning and story comprehension were correlated in our study, which is consistent with previous research (Strasser, Larrain \& Lissi, 2013). The lack of difference between interrupting and non-interrupting instruction is also consistent with Blewitt et al. (2009). The current study expanded on their findings by determining that children perform equally even with just one presentation of interactive vocabulary instruction. Further, the role of story comprehension was elucidated. Children did not have difficulty comprehending and remembering story events when words were explained interrupting the story or not interrupting the story. Previous studies had not discovered that a dialogic-like technique used more memory resources than teaching words before or after, in fact, when Ewers \& Brownson (1999) compared high-working memory to low-working memory children in a dialogic reading task they found no differences. Their single working memory measure was a test of nonword repetition and may not have been as robust as the current study's measures since we used both digit span and the self-ordered pointing task. 
One major difference between learning words in the context of the story and learning them separately from the story is the proximity to information that may be useful to infer the meaning of an unknown word. Previous studies (e.g. Justice, 2002) have used an expository text to introduce the new words. This may make the target words' meaning difficult to infer without extra-textual talk. Although the current study did provide children with a narrative and the words taught were depicted in the story's illustrations, we did not directly manipulate whether the target word could be inferred from the story context. In subsequent studies it will be important to investigate whether the role of instructional placement changes based on the story context. For example, in a story where understanding the target word is key for understanding the narrative will instruction on the word inside the story be more important than instruction on a word that is not central for understanding the storyline.

Many studies have found that children with larger lexicons acquire more words (Blewitt, et al., 2009; Ewers \& Brownson, 1999; Hindman, et al., 2008; Sénéchal, et al., 1995). In the current study, however, there was no word-learning advantage for children with higher PPVT-IV scores. This may be because our sample was positively skewed in terms of PPVT-IV scores. The average PPVT-IV score in our study was in the $83^{\text {rd }}$ percentile. This implies that we did not have enough variability in previous vocabulary knowledge to show a word learning difference and our results might have been different if we had included preschoolers with more average or impaired language abilities. This may have been the result of our sampling: we had a group of participants who came from upper income and education brackets. Given the established relationship between income and vocabulary size (Hart \& Risley, 1995; White, Graves, \& Slater, 1990) in future 
studies, it will be critical to recruit participants from a wider range of socio-economic brackets. Regardless, our findings clearly show that children in our sample effectively learned words regardless of whether the instruction occurred within or outside of the story. This finding suggests that for children with above average vocabulary sizes, it may be unnecessary to interrupt the reading of the story with instruction about vocabulary items.

The findings in this study elucidate the differences between teaching words during a narrative and outside of the narrative. Children's memory abilities predict performance on word learning tasks and story comprehension when the words are taught inside the narrative, but not when they are taught separately from the narrative. The fact that children are using more cognitive resources is not necessarily negative, but for children with impaired working memory, it may be more effective for them to learn difficult words before or after a story is read straight through. 


\section{REFERENCES}

Biemiller, A. (2003). Vocabulary: Needed If More Children Are To Read Well. Reading Psychology, 24(3-4), 323-335. doi:10.1080/02702710390227297

Blewitt, P., Rump, K. M., Shealy, S. E., \& Cook, S. A. (2009). Shared book reading: When and how questions affect young children's word learning. Journal of Educational Psychology, 101(2), 294-304.

Bus, A. G., Van IJzendoorn, M. H., \& Pellegrini, A. D. (1995). Joint Book Reading Makes for Success in Learning to Read : A Meta-Analysis on Intergenerational Transmission of Literacy. Review of Educational Research, 65(1), 1-21.

Cain, K., Oakhill, J., \& Bryant, P. (2004). Children's reading comprehension ability: Concurrent prediction by working memory, verbal ability, and component skills. Journal of Educational Psychology, 96(1) 31-42.

Carlson, S. M., Moses, L. J., \& Claxton, L. J. (2004). Individual differences in executive functioning and theory of mind: An investigation of inhibitory control and planning ability. Journal of Experimental Child Psychology, 87(4), 299-319. doi:10.1016/j.jecp.2004.01.002

Cragg, L., \& Nation, K. (2007). Self-ordered pointing as a test of working memory in typically developing children. Memory (Hove, England), 15(5), 526-35. doi:10.1080/09658210701390750

Dickinson, D. K., Golinkoff, R. M., \& Hirsh-Pasek, K. (2010). Speaking Out for Language: Why Language Is Central to Reading Development. Educational Researcher, 39(4), 305-310. doi:10.3102/0013189X10370204 
Dunn, L.M., \& Dunn, D.M. (2007). PPVT-IV: Peabody Picture Vocabulary Test - Fourth Edition. Circle Pines, MN: American Guidance Service.

Ewers, C., \& Brownson, S. (1999). Kindergarteners' Vocabulary Acquisition As a Function of Active Vs. Passive Storybook Reading, Prior Vocabulary, and Working Memory. Reading Psychology, 20(1), 11-20. doi:10.1080/027027199278484

Gathercole, S., Willis, C., Emslie, H., \& Baddeley, A. D. (1992). Phonological memory and vocabulary development during the early school years: A longitudinal study. Developmental Psychology, 28(5), 887-898. Retrieved from http://psycnet.apa.org/journals/dev/28/5/887/

Hargrave, A. C., \& Sénéchal, M. (2000). A Book Reading Intervention with Preschool Children Who Have Limited Vocabularies : The Benefits of Regular Reading and Dialogic Reading. Early Childhood Research Quarterly, 90(1), 75-90.

Hart, B., \& Risley, T. R. (1995). Meaningful differences in the everyday experience of young American children. Baltimore: Paul Brookes. Hieronymous,

Hindman, A. H., Connor, C. M., Jewkes, A. M., \& Morrison, F. J. (2008). Untangling the effects of shared book reading: Multiple factors and their associations with preschool literacy outcomes. Early Childhood Research Quarterly, 23(3), 330-350. doi:10.1016/j.ecresq.2008.01.005

Isbell, R., Sobol, J., Lindauer, L., \& Lowrance, A. (2004). The effects of storytelling and story reading on the oral language complexity and story comprehension of young children. Early Childhood Education Journal, 32(3), 157-163.

doi:10.1023/B:ECEJ.0000048967.94189.a3 
Justice, L. M. (2002). Word Exposure Conditions and Preschoolers' Novel Word Learning During Shared Storybook Reading. Reading Psychology, 23(2), 87-106. doi:10.1080/027027102760351016

Merriman, W. E., Bowman, L. L., \& Macwhinney, B. (1989). The Mutual Exclusivity Bias in Children's Word Learning. Monographs of the Society for Research in Child Development, 54(3), 1-129.

Mol, S. E., Bus, A. G., De Jong, M. T., \& Smeets, D. J. (2008). Added Value of Dialogic Parent-Child Book Readings: A Meta-Analysis. Early Education \& Development, 19(1), 7-26.

Montgomery, D. E., \& Koeltzow, T. E. (2010). A review of the day-night task: The Stroop paradigm and interference control in young children. Developmental Review, 30(3), 308-330. doi:10.1016/j.dr.2010.07.001

National Early Literacy Panel. (2008). Developing early literacy: Report of the National Early Literacy Panel. Washington, DC: National Institute for Literacy. Available at http://www.nifl.gov/earlychildhood/NELP/ NELPreport.html

Reese, E., \& Cox, A. (1999). Quality of adult book reading affects children's emergent literacy. Developmental Psychology, 35(1), 20-28. doi:10.1037//0012-1649.35.1.20

Scarborough, H. S., \& Dobrich, W. (1994). On the efficacy of reading to preschoolers. Developmental Review, 14, 245-302.

Scarborough, H. S., Dobrich, W., \& Hager, M. (1991). Preschool literacy experience and later reading achievement. Journal of Learning Disabilities, 24, 508-511. 
Sesma, H. W., Mahone, E. M., Levine, T., Eason, S. H., \& Cutting, L. E. (2009). The Contribution of Executive Skills to Reading Comprehension. Child Neuropsychol., 15(3), 232-246. doi:10.1080/09297040802220029.THE

Sénéchal, M. (1997). The differential effect of storybook reading on preschoolers' acquisition of expressive and receptive vocabulary. Jour- nal of Child Language, 24, 123-138.

Sénéchal, M., \& Cornell, E. H. (1993). Vocabulary Acquisition through Shared Reading experiences. Reading Research Quarterly, 28(4), 360-374.

Sénéchal, M., Thomas, E., \& Monker, J. (1995). Individual Differences in 4-Year-Old Children's Acquisition of Vocabulary During Storybook Reading. Journal of Educational Psychology, 87(2), 218-229.

Simpson, A., \& Riggs, K. J. (2005). Inhibitory and working memory demands of the daynight task in children. British Journal of Developmental Psychology, 23(3), 471486. doi:10.1348/026151005X28712

Spencer, E. J., Goldstein, H., Sherman, A., Noe, S., Tabbah, R., Ziolkowski, R., \& Schneider, N. (2012). Effects of an Automated Vocabulary and Comprehension Intervention: An Early Efficacy Study. Journal of Early Intervention, 34(4).

Strasser, K., Larraín, A., \& Lissi, M. R. (2013). Effects of Storybook Reading Style on Comprehension: The Role of Word Elaboration and Coherence Questions. Early Education \& Development, 24(5), 616-639. doi:10.1080/10409289.2012.715570

Strouse, G. a, O’Doherty, K., \& Troseth, G. L. (2013). Effective Coviewing: Preschoolers' Learning From Video After a Dialogic Questioning Intervention. Developmental Psychology. doi:10.1037/a0032463 
Walsh, B. a., \& Blewitt, P. (2006). The Effect of Questioning Style During Storybook Reading on Novel Vocabulary Acquisition of Preschoolers. Early Childhood Education Journal, 33(4), 273-278. doi:10.1007/s10643-005-0052-0

White, T. G., Graves, M. F., \& Slater, W. H. (1990). Growth of reading vocabulary in diverse elementary schools: Decoding and word meaning. Journal of Educational Psychology, 82, 281-290.

Whitehurst, G. J., Arnold, D. S., Epstein, J. N., Angell, A. L., Smith, M., \& Fischel, J. E. (1994). A Picture Book Reading Intervention in Day Care and Home for Children From Low-Income Families. Developmental Psychology, 30(5), 679-689.

Whitehurst, G. J., Falco, F. L., Lonigan, C. J., Fischel, J. E., Debaryshe, B. D., \& Caulfield, M. (1988). Accelerating Language Development Through Picture Book Reading. Developmental Psychology, 24(4), 552-559.

Wilkinson, K. S., \& Houston-Price, C. (2012). Once upon a time, there was a pulchritudinous princess .... The role of word definitions and multiple story contexts in children's learning of difficult vocabulary. Applied Psycholinguistics, 34(03), 591-613. doi:10.1017/S0142716411000889

Zucker, T. a., Justice, L. M., Piasta, S. B., \& Kaderavek, J. N. (2010). Preschool teachers' literal and inferential questions and children's responses during whole-class shared reading. Early Childhood Research Quarterly, 25(1), 65-83.

doi:10.1016/j.ecresq.2009.07.00 
Tables

\begin{tabular}{|lll|}
\hline & Inside condition & Outside condition \\
\hline Age (in months) & $54.87(8.68)$ & $53.57(8.61)$ \\
\hline Sex (proportion female) & .46 & .45 \\
\hline Maternal Education* & $5.73(1.34)$ & $5.56(1.43)$ \\
\hline Paternal Education* & $5.72(1.32)$ & $5.38(1.83)$ \\
\hline Income* & $5.74(1.84)$ & $5.56(1.93)$ \\
\hline $\begin{array}{l}\text { Number of Children's } \\
\text { books }\end{array}$ & $131.71(67.49)$ & $117.00(93.16)$ \\
\hline Hours read per week & $3.73(2.65)$ & $4.20(2.68)$ \\
\hline PPVT-IV raw score & $99.00(24.04)$ & $95.59(23.59)$ \\
\hline Digit span & $6.35(1.48)$ & $6.10(1.52)$ \\
\hline Inhibition & $14.72(4.14)$ & $14.32(4.64)$ \\
\hline Self Ordered Pointing Task & $19.05(1.71)$ & $19.24(2.65)$ \\
\hline
\end{tabular}

Table 1: Means and standard deviations per condition. *Maternal education, paternal education and income were given a value from 1-7.

\begin{tabular}{|lll|}
\hline & Inside condition & Outside condition \\
\hline Pretest & $2.33(1.16)$ & $2.32(.85)$ \\
\hline Posttest & $3.33(1.33)$ & $3.69(1.39)$ \\
\hline Generalization & $3.18(1.58)$ & $3.10(1.61)$ \\
\hline Story Comprehension & $3.88(1.25)$ & $3.45(1.17)$ \\
\hline
\end{tabular}

Table 2: Mean out of six (standard deviation) of target word selected (chance $=2$ )

\begin{tabular}{llll}
\hline Predictors & B & SE B & $\boldsymbol{\beta}$ \\
\hline Age (mo) & .02 & .08 & .05 \\
\hline Digit-Span & .13 & .37 & .08 \\
\hline Inhibition & .08 & .12 & .15 \\
\hline SOPT & -.002 & .17 & -.002 \\
\hline
\end{tabular}

Table 3: Outside condition. Dependent variable: combined vocabulary Post-test and Generalization scores. Model n.s. $F(4,32)=.36, p=.835$. 


\begin{tabular}{llll}
\hline Predictors & B & SE B & $\boldsymbol{\beta}$ \\
\hline Age (mo) & .04 & .05 & .12 \\
\hline Digit-Span & .75 & .24 & $.43^{*}$ \\
\hline Inhibition & .15 & .09 & .24 \\
\hline SOPT & .18 & .21 & .23 \\
\hline
\end{tabular}

Table 4: Inside condition: Dependent variable: combined vocabulary Post-test and Generalization scores. $F(4,36)=7.80$.

\begin{tabular}{lccc}
\hline Predictors & B & SE B & $\boldsymbol{\beta}$ \\
\hline Age (mo) & .04 & .04 & .28 \\
\hline Digit-Span & .14 & .16 & .18 \\
\hline Inhibition & .01 & .05 & .04 \\
\hline SOPT & .07 & .07 & .14 \\
\hline PPVT-IV & .02 & .01 & .31 \\
\hline
\end{tabular}

Table 5: Outside condition: Dependent variable: Story comprehension. F $(5,36)=3.24 p$ $<.05, R_{\text {Adjusted }}^{2}=0.24$. 


\begin{tabular}{llll}
\hline Predictors & B & SE B & $\boldsymbol{\beta}$ \\
\hline Age (mo) & .03 & .02 & .21 \\
\hline Digit-Span & .27 & .12 & $.31^{*}$ \\
\hline Inhibition & -.03 & .05 & -.09 \\
\hline SOPT & .27 & .11 & $.37 *$ \\
\hline PPVT-IV & .00 & .01 & .28 \\
\hline
\end{tabular}

Table 6: Inside condition: Dependent variable: Story comprehension. $F(5,40)=5.67, p$ $<.001, R_{\text {Adjusted }}^{2}=0.37$. 

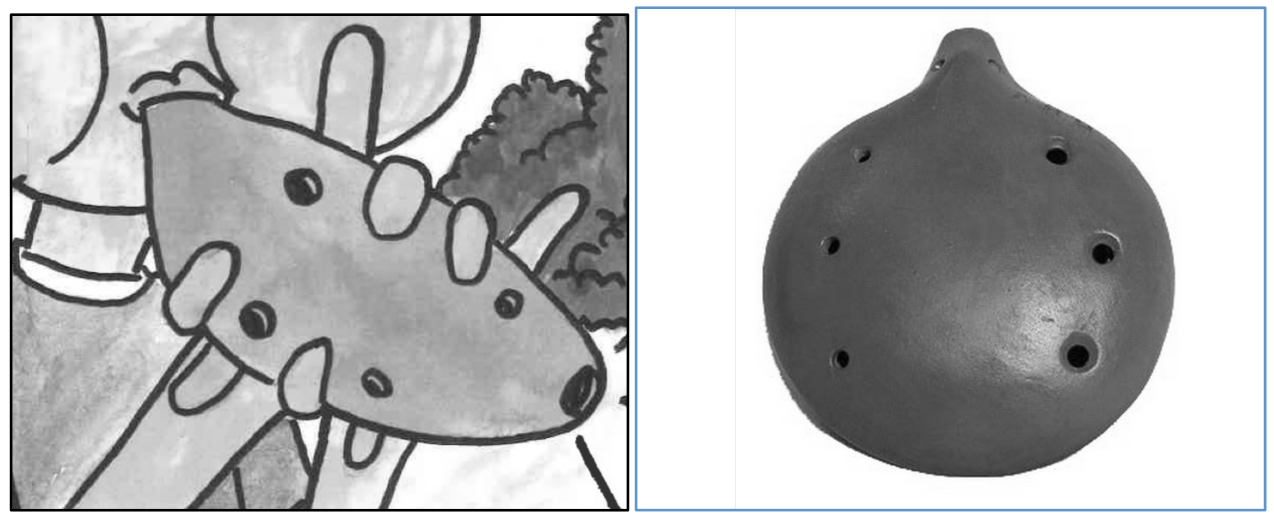

Figure 1: Examples of Vocabulary Cards (ocarina)

a) used for pre-test and post-test

b) used for generalization

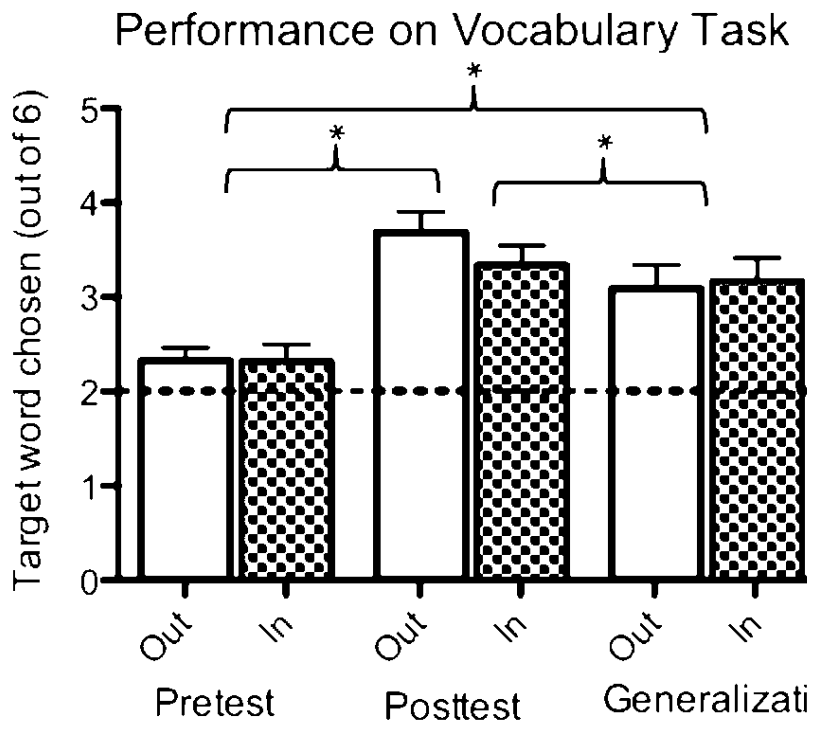

Figure 2. Performance on pretest, posttest, and generalization in the two conditions. 


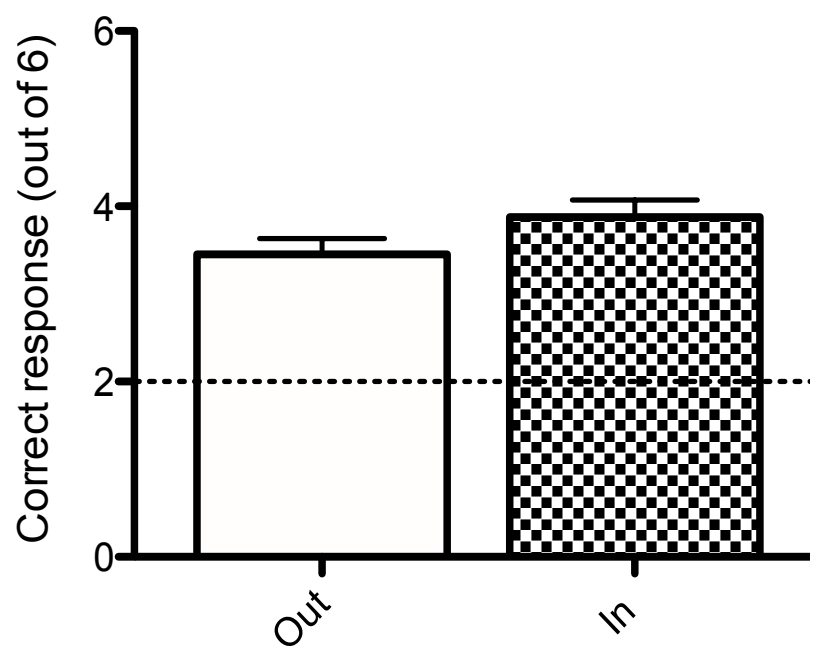

Figure 3: Performance on story comprehension in the two conditions. 